\title{
ARTIGODERUEX̃̃O
}

\section{Puncionando a veia bailarina}

\author{
Maria Aparecida de Luca Nascimento ${ }^{1}$ \\ Maria Filomena P.V. Almeida ${ }^{2}$ \\ Fernando Porto ${ }^{3}$ \\ Thereza Christina dos S. F. Cardoso ${ }^{4}$
}

\section{Resumo}

Estudo descritivo idealizado a partir da observação do modo repetitivo e institucionalizado, através do qual a punção venosa periférica em crianças vem sendo realizada. Os autores perceberam que a realização deste procedimento contempla a racionalização do tempo, mesmo quando não é de urgência, em detrimento de outros fatores importantes. Com o objetivo de destacar a relevância dos aspectos fisiológicos e emocionais envolvidos no momento do procedimento, é apresentado o modo de abordagem da técnica, com os alunos em campo de ensino clínico. Considerando que a punção venosa pediátrica de “veia bailarina” é um desafio para a equipe de enfermagem, concluiu-se que a destreza e a habilidade na punção de uma veia periférica em crianças, como em qualquer outro caso, são adquiridas através da repetição deste procedimento. Entretanto, se a equipe de enfermagem atentar para a sua visão ontológica, o sucesso na realização vai além da introdução da agulha em um seio venoso.

Palavras-chave: Enfermagem pediátrica - Punção venosa - Cuidado de enfermagem

Abstract

\section{Punctioning the "dancer vein"}

This is a descriptive study was idealized from teachers' observation of pediatric nursing during the clinical teaching. They perceived that the pediatric intravenous punction was implemented at the same way, where the most important thing was the time to realize this nursing procedure. The main goal is to show relevant points must be observed during the pediatric intravenous punction, based on physiological and emotional aspects. Considering that this nursing procedure is a great challenge for the nursing team, specially when the pediatric vein is like a dancer, the authors concluded that the nursing sucess in this case go ahead to put a needle into the pediatric vein.

Key-words: Pediatric nursing - intravenous punction - Nursing care

\section{Resumen}

\section{La punción de la vena "baialrina"}

Esto estudio descriptivo fué idealizado a partir de la observación del modo repetitivo e institucionalizado, de la realización de la punción venosa perisférica en niños. Los autores, profesores de la disciplina de enfermería pediátrica de la Universidad Pública de Rio de Janeiro, percibieron que en el procedimiento en mención,

1 Professor Adjunto do Departamento de Enfermagem Materno- Infantil (DEMI) da Escola de Enfermagem Alfredo Pinto (EEAP) da Universidade do Rio de Janeiro (UNIRIO) - Coordenadora do núcleo de Pesquisa em Saúde da mulher e da Criança Doutora em Enfermagem.

2 Professor Adjunto do DEMI da EEAP da UNIRIO - Mestre em Enfermagem.

3 Professor Auxiliar do DEMI da EEAP da UNIRIO

4 Professor Auxiliar do DEMI da EEAP da UNIRIO 
normalmente, al ser realizado contempla la racionalización del tiempo, mismo cuando la situación no es de urgéncia, aun en presencia de otros factores importantes. Teniendo como principal objetivo destacar la relevancia de los aspectos fisiológicos y emocionales en en cual se ven envueltos en ese momento del procedimiento, dichos autores presentam el modo por el cual esta técnica es abordada con sus alumnos durante la enseñanza clínica. Considerando que la punción venosa pediátrica siempre es un desafio para el equipo de enfermeros (as) en especial la vena “baialrina”, concluyendose que la destreza y la habilidad en la punción de una vena perisférica en niños, como en cualquier otro caso, son adquiridas a través de la repetición de este procedimiento, entonces si el equipo de enfermeros esta atento para su visión ontológica, el éxito de la realización no estará relacionado solamente al hecho de conseguir introducir una aguja en el seno venoso.

Palabras claves: Enfermería pediátrica - Puncción venosa - Cuidad de enfermería

\section{INTRODUÇÃO}

A preocupação em escrever este estudo, surgiu da necessidade que nós, professores da disciplina enfermagem pediátrica, sentimos, ao percebermos o modo pelo qual a punção venosa pediátrica vem sendo realizada pelos profissionais de enfermagem.

Esta percepção acontecia nas instituições hospitalares onde trabalhávamos desenvolvendo, tanto a nossa prática assistencial isolada, quanto a nossa prática docente.

Como enfermeiros da assistência, na nossa na prática profissional isolada, observávamos que a técnica de punção venosa pediátrica, era realizada de forma a privilegiar a racionalização do tempo, mesmo quando a situação não era de urgência. Considerando este aspecto, a pressa era uma constante quando da realização do procedimento em apreço. Por conta desta determinante, era eleito o profissional "bom de veia".

Desta forma, o profissional acima citado, que normalmente era aquele que menos tempo levava para realizar a punção venosa, era sempre solicitado quando havia uma veia a ser puncionada. Este fato permitia que ele exercitasse cada vez mais essa capacidade, adquirindo, cada vez mais, destreza e habilidade. Em compensação, os outros profissionais, ao lhe delegarem a sua própria função, permitiam que houvesse, não só o rompimento do caráter holístico da assistência de enfermagem à criança, como também a perda de oportunidade de desenvolverem as mesmas características que ele.

Este situação ao ser reportada para a nossa prática docente em campo de ensino clínico, nos levou a perceber que a destreza e a habilidade dos profissionais que realizavam a punção venosa pediátrica, inibiam os acadêmicos de enfermagem, que ao serem solicitados para desenvolverem a técnica em apreço, mostravam-se temerosos, apesar da presença do professor ao seu lado.

A disciplina enfermagem pediátrica ao ser abordada no último período de graduação, permitindo que o primeiro contato com o cliente pediátrico hospitalizado se dê nesta época, confere ao acadêmico de enfermagem, uma grande ansiedade e insegurança, por conta, entre outros fatores, dos tratamentos dolorosos que são impostos à criança.

Este comportamento, mencionado no estudo intitulado “Uma criança no meu caminho" (Nascimento et al, 1997, p.8) que apresentado no $49^{\circ}$ Congresso Brasileiro de Enfermagem, também foi atribuído à expectativa da formatura, que sempre é um marco referencial para os acadêmicos, pois prenuncia e enseja grandes mudanças em suas vidas.

Na conclusão do estudo supra referenciado, ficou constatado que a maioria dos acadêmicos (65\%) não optariam pela enfermagem pediátrica quando do seu futuro exercício profissional. Em contrapartida, a equipe de professores da disciplina, sugeriu que novas abordagens fossem feitas durante o ensino clínico para que esta escolha fosse feita desprovida de conceitos pré existentes.

Esse estudo tem esta finalidade, abordar de uma forma diferenciada o grande desafio que é a punção venosa pediátrica para o acadêmico de enfermagem considerando a sua ansiedade, sua expectativa, sua inibição diante da destreza dos profissionais na execução da técnica em referência, e acima de tudo, enfatizar a importância dos 
passos metódicos que cumprimos para que a mesma seja realizada de forma a proporcionar confiança a quem é cuidado, e segurança a quem cuida.

\section{OBJETIVOS}

- Descrever o método utilizado pelos professores da disciplina Enfermagem Pediátrica para orientar os acadêmicos na execução da técnica de punção venosa periférica em campo de ensino clínico, tendo em vista a sua insegurança e ansiedade diante da realização deste procedimento,

- Correlacionar os aspectos; fisiológicos, anatômicos e emocionais, que se vêm envolvidos durante a execução da técnica da punção venosa periférica em pediatria, ao método adotado pelos professores da disciplina Enfermagem Pediátrica para a sua consecução

- Propor à equipe de enfermagem uma reflexão acerca do modo pelo qual os procedimentos técnicos repetitivos estão sendo realizados, com vistas à reformulação dos paradigmas que vêm sendo adotados para a sua consecução.

\section{A VEIA "BAILARINA"}

Como em todo o procedimento técnico, existe na punção venosa pediátrica, u‘a margem de erro e de riscos previsíveis, que estão presentes em todas as suas etapas, desde o seu planejamento, até à sua fixação. No entanto, parece haver contida na etapa da penetração da agulha no seio venoso, uma maior preocupação não só da equipe de enfermagem, como também, e principalmente, dos acompanhantes das crianças que a ela são submetidas.

Esta preocupação, segundo a nossa própria experiência, é visualizada através da tentativa de penetrar com a agulha no seio venoso, no menor espaço de tempo possível.

Deste modo, o desafio que é puncionar uma veia periférica em pediatria potencializa-se, pois além de ter-se que introduzir uma agulha no braço de uma criança há que se enfrentar a incerteza de conseguir-se este intento na primeira tentativa.

A incerteza na consecução da punção na primeira tentativa, decorre, entre outros fatos, pela presença da veia “bailarina”, que é uma característica que confere ao vaso, a propriedade de deslocar-se, dentro da tela subcutânea.

Por conta deste, e de outros fatores, devemos nos resguardar ao máximo das possíveis eventualidades que possam ocorrer, quando da punção de uma veia periférica em pediatria.

Tendo em vista as peculiaridades da criança passamos a enumerar as etapas a serem seguidas para a realização do procedimento técnico propriamente dito, assim como as justificativas para a sua adoção.

Importante se faz ressaltar que, além do enfoque teórico que respalda a prática, a equipe de professores preocupa-se também com outros aspectos relacionados à ergonomia, bio- segurança, auto- estima, fatores que contribuem para a formação do perfil profissional do futuro enfermeiro.

\section{ENSINANDO EPREVENINDO}

As etapas que se seguem, são aquelas adotadas no ensino clínico, uma vez que este estudo reproduz a nossa prática cotidiana. Porém, há que se considerar o caráter dinâmico de todo e qualquer procedimento, por isto estas etapas, vez por outra, podem ser alteradas e/ou modificadas. Elas foram elaboradas de modo a atingir o acadêmico de enfermagem, por este motivo, a forma redacional que se segue:

\section{$1^{\circ}$ PASSO - Consultar a prescrição, conferindo o} nome da criança e a medicação a ser preparada - Em pediatria, a ocorrência de homônimos é muito freqüente, assim como, nomes onde uma única vogal é que faz a diferença. Deste modo, é importante consultar a acompanhante. Na sua falta, e no caso de lactentes, a certeza poderá advir da consulta à pulseirinha de identificação, que deverá conter o número do prontuário da criança.

Uma vez identificada a criança, deve-se proceder ao preparo do rótulo da solução. Esta providência tem as seguintes finalidades: Liberar a folha de prescrição para os outros profissionais, e também garantir que a mesma não seja danificada ao ser colocada sob a bancada de medicação. Nesta oportunidade, enfatiza-se a importância da folha de prescrição como sendo um documento.

A confecção do rótulo da solução em pediatria, vai permitir a você planejar a sua atividade de acordo com os medicamentos que serão necessários, atentar para os 
percentuais de diluição dos mesmos, preencher de forma a fornecer todas as informações necessárias com relação à solução, tais como: nome e número do leito da criança, componentes da solução e seus respectivos mililitros, total da solução (em mls) - Numero da etapa da solução Início da mesma - Tempo previsto para o seu fluxo - data - assinatura de quem preparou. A importância do rótulo é tão grande, que você deve prepará-lo sentado e atentamente.

Uma vez o rótulo pronto, dimensionando além da medicação a ser utilizada, o material para o seu preparo, passamos à outra etapa.

\section{$2^{\circ}$ PASSO - Conversar com a criança}

Esta conversa inicial tem como objetivo apresentar-se , pelo nome à criança, afinal, mais do que ninguém ela sabe quem é a(o) sua (seu) verdadeira(a) tia (o). Porém, se ela identificá-lo desta forma, mesmo, assim, apresente-se. Lembre-se que ninguém confia em quem não conhece, pelo menos, o nome. Ao apresentar-se, certifique-se da faixa etária da criança, e da sua rede venosa periférica, compatibilizando-a à solução a ser infundida com a finalidade de planejar o calibre do escalpe a ser utilizado.

$3^{\circ}$ PASSO - Lavar as mãos - Esta etapa é imprescindível à realização de qualquer procedimento técnico em enfermagem

$4^{\circ}$ PASSO - Preparo do material e da solução - De posse do rótulo preparado, comece a separar o material que será utilizado; frasco de solução glicosada (se for o caso), eletrólitos, agulhas para a retirada dos eletrólitos das seringas para serem adicionados à solução, equipo de soro, escalpe.

\section{$5^{\circ}$ PASSO - Preparo da bandeja de punção venosa} pediátrica - Ao preparar uma bandeja de punção venosa pediátrica, lembre-se que o material a ser utilizado deverá ser revisado ao sair da embalagem, sob pena de trazer prejuízos na hora da punção. Desta forma, teste o escalpe injetando-lhe solução glicosada. Este teste permitirá observar defeitos de fabricação, tais como imperfuração da agulha, e desajuste na sua inserção ao "butterfly”. Além disto, preenchendo a luz do escalpe, preserva-se não só a criança, pela possibilidade de perder-se a veia pela coagulação do sangue no seu trajeto, como também a quem punciona, pois evita a possível contaminação pelo contato com o sangue. A bandeja deverá levar em seu interior, todo o material para lhe dar segurança e tranqüilidade. Como o objeto do nosso cuidado é a criança, prepare-a de modo a impressioná-la o menos possível. Desta forma, levaremos em seu interior:

O impermeável, que deverá ser colorido, estimulando a visão da criança. Além de permitir delinear a área de ação, evitará que, a roupa de cama seja atingida caso haja extravasamento de sangue ou solução.

Bolinhas de algodão. Por experiência, observamos que a capa do invólucro das seringas de 5 e de $10 \mathrm{ml}$, formam uma perfeita bandeja para o acondicionamento de 4 a 5 bolinhas de algodão, permitindo que as mesmas sejam embebidas, ainda durante o preparo do material, com a solução que será utilizada para a anti-sepsia cutânea, e assim permaneçam até na hora da punção.

Escalpe acoplado à seringa com solução glicosada Conforme citado anteriormente, este equipamento acondicionado na bandeja, já deverá ter sido previamente testado, e analisado quanto à compatibilidade de seu calibre com a infusão a ser realizada. cada tentativa de punção venosa na mesma criança, deverá ser utilizado um novo escalpe.

Solução prescrita - previamente rotulada, que deverá ser levada ao local da punção, para ser imediatamente instalada após a punção, sendo registrado então, no rótulo pré existente, a hora do início do fluxo e o numero de microgotas a serem infundidas por minuto.

Tiras de esparadrapo - É importante perceber que as tiras de esparadrapo deverão ser compatíveis com a estrutura da região a ser puncionada e levá-las, previamente cortadas e acondicionadas na bandeja, evitará que este trabalho seja feito na hora da punção, sob risco de perder-se a veia. Além das tiras, leve também o rolo de esparadrapo, caso haja necessidade, você não precisará se deslocar.

Garrote, que deverá ser utilizado, caso não seja possível proceder-se ao bombeamento com a mão. Este procedimento permite dimensionar melhor a pressão que é exercida sobre o local, preservando não só o vaso, como também as válvulas, que são estruturas anatômicas importantes.

Tala para a imobilização do membro, caso a punção seja de uma veia periférica em membro superior. 
Luvas de procedimento - Atente para os aspectos da biosegurança.

Recipiente plástico, que deverá ser utilizado para desprezar material, tem a finalidade de evitar contaminação com o material descartado, e no caso de objetos perfurantes ou cortantes, evitar acidentes.

$6^{\circ}$ PASSO - Encaminhar-se ao leito da criança. O material planejado acondicionado na bandeja tem a finalidade de racionalizar tempo e movimento, desta forma, a realização da técnica propriamente dita, é a próxima etapa a ser seguida.

\section{ENFRENTANDO ODESAFIO}

Se a situação não for de urgência, há que se considerar alguns aspectos no que diz respeito, não só, à eleição do vaso a ser puncionado, como também, o ambiente onde este procedimento irá se realizar.

O ambiente acima referenciado, deve ser claro e tranqüilo. Caso haja necessidade, desloque a criança para realizar o procedimento. Fique na altura dela, se for preciso, sente-se e apoie o material com segurança, evitando acidentes. Ao apoiar o material, nunca no próprio leito da criança, que a qualquer reação poderá inutilizá-lo e/ou causar acidentes, posicione o recipiente para a coleta do material descartável.

É imprescindível que você esteja à vontade e tranqüilo. Para que isto aconteça, observe a sua postura, ela deve proporcionar a você conforto e segurança para realizar a punção venosa. Preocupe-se com os aspectos relacionados à ergonomia, afinal, você está apenas começando a praticar uma profissão que exigirá esta observação durante toda a sua vida, para que você viva melhor, sem as conhecidas e estudadas "doenças profissionais”.

Após a observação dos itens acima mencionados, aborde a criança, e, de acordo com o seu nível de entendimento, explique-lhe o que vai ocorrer, não a pegue desprevenida e, sobretudo, não a engane, muitas vezes a criança até colabora com o profissional na hora da punção venosa.

É muito importante consultar-se a mãe, não só com relação ao local da punção, como também, com relação à sua vontade em permanecer, ou não, ao lado da criança na hora da punção. Em caso de lactentes, quando as veias epicranianas são muito utilizadas, raspar parte do couro cabeludo que contém um “cachinho” representa para a mãe, mais uma agressão que um cuidado. Neste caso, se houver outra via de acesso, é só substituir.

Importante também, é considerar que a imobilização do membro, no caso da punção venosa ocorrer no braço, impossibilitará a criança que chupa o dedo para se consolar, possa fazê-lo. Havendo outra via de acesso, opte pelo braço oposto.

Após a eleição criteriosa do vaso, que deverá priorizar a sua ascendência, pois no caso de infiltração, o mesmo vaso poderá ser puncionado mais acima, vista a luva e garroteie o membro, observe a possibilidade de fazê-lo bombeando-o manualmente, evitando desta forma, a pressão contínua com o garrote de borracha, que poderá tensionar o vaso e as válvulas acima da sua capacidade de resistência, podendo rompê-los.

Segundo Guyton (1984, p.125) a distensão ou estiramento dos tecidos causam dor, sensação que pode ser creditada à deformação que é imposta às terminações nervosas. Considerando que as veias possuem inervações, comandadas pelo sistema nervoso simpático, ao longo do seu trajeto, podemos concluir que os “tapinhas” que são aplicados na criança, a título de promover o enchimento venoso, causam dor, e por isto devem ser abolidos.

A anti-sepsia cutânea deve ser de modo a preservar as válvulas venosas. Desta forma, proceda-a no sentido da corrente venosa, isto é; centripetamente em relação ao coração.

A etapa da introdução da agulha no seio venoso requer todo o cuidado, visualize bem o vaso e tracione os seus limites para a introdução da agulha que deverá ser feita, a título de segurança, lateralmente ao vaso que será puncionado, atingindo a tela subcutânea.

Esta introdução lateral objetiva evitar que a pressão exercida para o rompimento da pele, que será variável de acordo com o seu nível de hidratação, transfixie a veia.

A tração dos limites do vaso previne o seu deslocamento na tela subcutânea, ademais se ele possuir as características próprias da veia bailarina. 
Uma vez atingida a tela subcutânea, o "pico” no tecido venoso, poderá ser de forma mais calculada permitindo a introdução da agulha por inteiro na luz do vaso. Além disto, a tração dos limites do vaso eleito fornecerá maior confiança a quem pratica a sua punção, pois a pressão exercida para a perfuração do tecido venoso, que diferencia estruturalmente do tecido epitelial do braço, será exercida unicamente com esta finalidade.

Detalhadamente projetada, a estrutura delgada do tecido venoso é constituída por três camadas; íntima, média e adventícia. (Porto;1997, p.416)

Segundo Brunner ( 1996; p.624 ), estas camadas seriam assim constituídas; a mais interna (íntima) - tecido endotelial, a mediana (média) - tecido elástico liso, e a mais externa (adventícia) - tecido conjuntivo.

Diante destas características, conclui-se que puncionar uma veia consiste, tecnicamente, em romper com uma agulha, diversos tecidos (epitelial, subcutâneo, conjuntivo, elástico liso, e endotelial). Desta forma, a pressão gradativa exercida para a perfuração, por etapas, dos tecidos, possibilitará maiores chances de sucesso no procedimento.

Ao puncionar-se um vaso, o sangue reflui no escalpe. Se a veia for epicraniana, observe a sua coloração. Se estiver muito vermelho, indicando maior oxigenação, e se no local de inserção da agulha houver isquemia, retire rapidamente a agulha e pressione, há grande possibilidade de ter havido a punção de uma artéria, que em lactentes, são muito superficiais nesta região.

Um modo de prevenir esta ocorrência, é verificar-se, através da percepção na polpa digital, se o vaso é pulsátil.

Após a constatação do sucesso da punção, teste a higidez do vaso injetando com cuidado a solução glicosada contida no escalpe. Além desta finalidade, esta providência evita também que o sangue coagule no seu trajeto, pois o escalpe pediátrico possui um pequeno calibre, projetado que foi, proporcionalmente ao calibre da veia de crianças.

Após o teste, conecte o equipo de soro e proceda à fixação do escalpe no local da punção, atentando para a colocação das tiras de esparadrapo que foram previamente projetadas e cortadas. Verifique, após a fixação, se o gotejamento da solução sofreu alteração. Caso tenha ocor- rido, atente para o posicionamento da ponta da agulha no seio venoso, que poderá estar encostando na parede do vaso.

Esta situação pode ser sanada com a colocação de um calço embaixo do escalpe, que é confeccionado em nossa prática com alguns fios de algodão, e colocado embaixo do escalpe, com uma pequena espátula, obtida com a improvisação da capa de proteção da agulha do escalpe.

A imobilização da criança, se a punção ocorreu no seu braço, deverá ser feita através da tala imobilizadora seguindo critérios estipulados no estudo “ A síndrome da criança com o membro imobilizado para infusão venosa” (Nascimento, 1996, p. 122), e que, por ser uma técnica coadjuvante à punção venosa, não será tratada neste estudo.

Despeça-se da criança, e demonstre afeto por ela. Esta atitude, observada na nossa prática, tem mudado a reação das crianças com relação à uma agulha de punção.

Antes de retirar-se do local, proceda a uma última supervisão do local da punção e do gotejamento da solução. Despreze o material seletivamente e de acordo com as medidas universais de controle da infecção e biosegurança.

\section{CONCLUSÃO}

A preocupação em escrever este estudo, partiu da nossa atividade docente, ao percebermos a insegurança do acadêmico de enfermagem na hora da punção venosa pediátrica. Ao constatarmos que a prática da punção venosa pediátrica é apreendida pelo processo do reprodutivismo, e que os livros técnicos prendem-se à esfera do planejamento de material, começamos a entender o procedimento em destaque.

Vale ressaltar que, ao adotarmos os critérios descritos neste estudo para a realização da técnica em apreço, os acadêmicos de enfermagem assumem uma atitude reflexiva e começam a perceber a intensidade de um procedimento tão simples e complexo ao mesmo tempo. Em contrapartida eles passam a entender melhor a extensão da prática científica da enfermagem.

Por conta desta observação e de outras reflexões este estudo surgiu, e com ele, a proposta de que novos estudos surjam a partir da prática propriamente dita. 
À medida que um procedimento técnico é realizado, as adaptações, associações de conhecimentos e improvisações são feitas, desta forma, grandes mudanças são observadas a cada dia, que, se não escritas, permanecem na esfera do desconhecido.

Interferir nestas mudanças, ajustando-as aos conhecimentos científicos, é assegurar à criança, e a toda clientela, uma assistência de enfermagem, cujos riscos fiquem tão somente no terreno das possibilidades.

Deste modo, é mister a reflexão da equipe de enfermagem, acerca do modo pelo qual os procedimentos técnicos repetitivos estão sendo realizados e ensinados, visando a reformulação dos paradigmas (o modelo que preconiza o tempo como base para a sua realização) que vêm sendo adotados para a sua consecução.

Puncionar uma veia com sucesso, requer do profissional de enfermagem, muito mais que tão somente penetrar com uma agulha o seio venoso. Se além deste fato conseguirmos atentar para os aspectos que foram citados neste estudo, que privilegiam uma visão ontológica da criança, durante a realização do procedimento em apreço, acreditamos que não terá sido em vão termos tentado transcrever a nossa prática, que apesar de rotineira, sem- pre se vê modificada em prol da qualidade prestada, nos permitindo a cada dia, também aprender.

Cabe ressaltar que a atenção a todos estes aspectos , não garante o sucesso na realização da punção venosa em pediatria, tendo em vista o caráter dinâmico e imprevisível da assistência de enfermagem. Contudo, não conseguir puncionar uma veia, em especial a bailarina, não quer dizer que o passo a passo adotado tecnicamente foi ineficaz, e nem tão pouco este fato, deve ser gerador de sensação de fracasso em quem o realiza.

Ao transpormos para o papel, a nossa prática de ensino clínico, com relação à punção venosa pediátrica, acreditamos que expusemos alguns aspectos que são comuns a vários acadêmicos e professores de enfermagem, possibilitando a discussão sobre a nossa prática.

Discutir o "fazer" em enfermagem, atentando para as dimensões científicas contidas nos procedimentos mecânicos e rotineiros, é equacionar cientificamente a nossa profissão, e o que nos possibilita ensiná-la, é o aprendizado que com ela adquirimos.

"Mestre não é aquele que ensina é aquele que ajuda a aprender" (Khalil Gibran)

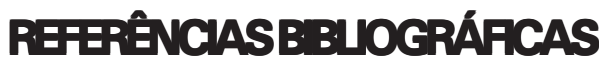

BRUNNER e SUDDARTH. Tratado de Enfermagem Médico-Cirúrgica. 8 ed Guanabara Koogan ,vol. 1, 1996. 822p.

DANGELO, J. G. e FATTINI, C. A. Anatomia Básica dos Sistemas Orgânicos. Rio de Janeiro: Atheneu, 1984.

GARDNER, E. et al. Anatomia._Trad. Liberato Dio. Rio de Janeiro. 2 ed. Gunabara Koogan, 1967. P 122. 891p

GUYTON, A. Fisiologia Humana. 6ed. Rio de Janeiro:Guanabara Koogan. 1984. 564p.

KOCH, R. M. et al. Técnicas Básicas de Enfermagem. 2 ed. Curitiba: Lítero - Técnica, 1978. 119p.

NASCIMENTO, M. A. L. A Síndrome da Criança com Membro Superior Imobilizado para Infusão Venosa. 1997.135f. Tese (Doutorado em Enfermagem). Escola de Enfermagem Anna Nery - Universidade Federal do Rio de Janeiro, Rio de Janeiro.

NASCIMENTO, M. A. L. et al - Uma Criança no Meu Caminho. In: 49 CONGRESSO BRASILEIRO DE ENFERMAGEM, 49, 1997, Belo Horizonte, RESUMOS. Minas Gerais: Associaçào Brasileira de Enfermagem - Secção MG, 1997.

PORTO, C. C. Semiologia Médica. 3 ed. Rio de Janeiro: Guanabara Koogan, 1997.

SALTER, R. B. Distúrbios e Lesões do Sistema Músculo-Esquelético. Medsi . 2 ed. 1985. 